\title{
Sobre a trajetória de professoras negras na pós-graduação em Ciência da Computação: alguns resultados preliminares
}

\author{
Ecivaldo S. Matos, Emilayne F. Corlett, Ana Carolina C. Ferreira, Juliana Maria \\ Oliveira dos Santos \\ Departamento de Ciência da Computação - Universidade Federal da Bahia (UFBA) \\ 40.170-110 - Salvador - BA - Brasil \\ \{ecivaldo, emilayne.corlett\}@ufba.br, \{anacarolina, \\ joliveira\}@dcc.ufba.br
}

\begin{abstract}
This paper presents partial results about the trajectory of blackwomen professors of graduate programs in Computer Science in Brazil. The data were collected by questionnaire and interview. It was identified qualitative aspects that characterize these trajectories and that may encourage girls and women to pursue a career in Computer Science.
\end{abstract}

Resumo. Este artigo apresenta resultados parciais sobre a trajetória de mulheres negras docentes da pós-graduação em Ciência da Computação no Brasil. Por meio de questionário e entrevista, foram identificados elementos qualitativos caracterizadores dessas trajetórias e que podem incentivar meninas e mulheres a seguir carreira na Ciência da Computação.

\section{Introdução}

Ainda não há estudos conclusivos sobre a participação de negros e negras no corpo docente de programas de pós-graduação em Ciência da Computação. Todavia, estudos sérios têm sido realizados para discutir a presença, a atuação e os perfis de mulheres atuantes na Ciência da Computação, como os realizados por Oliveira, Moro e Prates (2014).

Ainda assim, há um longo caminho a se fazer no sentido de mais estudos históricos, antropológicos e sociotécnicos para autoconhecimento da Ciência da Computação. Nesse sentido, os autores encaminharam uma pesquisa piloto para identificar casos de professores e professoras negros e negras atuantes como docentes da pós-graduação em Ciência da Computação. O principal objetivo por trás dessa pesquisa foi descortinar trajetórias de sujeitos cuja formação se deu em uma época em que não havia largos debates sobre ações afirmativas na graduação, tampouco na pósgraduação.

Por meio de questionário e entrevista, identificou-se elementos qualitativos que podem caracterizar as trajetórias de alguns desses sujeitos com a perspectiva de incentivar outros estudos sobre a trajetória de negras e negros na Ciência da Computação.

Neste artigo, apresentaremos um recorte, em que apresentamos dados introdutórios sobre o perfil das mulheres negras investigadas. Os resultados desta pesquisa devem ser disponibilizados pela Fundação Carlos Chagas ainda em 2017.

\section{Metodologia}

Dada a natureza do objeto de investigação, descritivo-analítico, e dos objetivos de pesquisa, foram utilizadas duas técnicas fundamentais para coleta de dados (em duas 
etapas): questionário e entrevista.

O questionário foi concebido utilizando a plataforma Google Forms ${ }^{\odot}$, escolhida por proporcionar oportunidade de trabalho colaborativo entre a equipe, por facilitar a organização dos dados para futuras análises, por ser uma plataforma personalizável e possuir opções de perguntas, de múltipla escolha a listas suspensas e escalas lineares. Para validação das questões de acordo com as variáveis de pesquisa foi executado préteste com alguns sujeitos. Após o pré-teste, o questionário foi ajustado e seguiu para divulgação e disponibilização pública. As entrevistas foram realizadas por adesão. Foram convidados a participar da etapa de entrevistas todos aqueles que estavam dentro do perfil pesquisado e responderam o questionário aceitando participar de outra rodada de coleta de dados.

\section{Alguns resultados parciais}

Nesta pesquisa piloto o questionário ficou disponível para recebimento de respostas durante 36 dias, período no qual recebeu contribuições de 49 pessoas distribuídas em 13 estados da Federação, com um percentual de 60\% das contribuições oriundas dos estados da Bahia e de São Paulo. Responderam ao questionário 21 pessoas do gênero feminino, das quais sete definem-se como brancas, sete pardas e sete pretas. Entre as pessoas de cor parda, uma não soube responder se é negra e outra respondeu que não se considera negra.

Para o presente recorte serão consideradas apenas as pessoas do gênero feminino e negras (pretas e pardas), totalizando 14 professoras. O escopo da pesquisa não considerou pessoas que possuíam como maior titulação a graduação ou que nunca tinham atuado na pós-graduação stricto-sensu em Computação no Brasil. Desta forma, das 14 professoras que responderam ao questionário, sete não responderam o questionário em toda sua extensão, por não terem atuação na pós-graduação strictosensu; portanto, não foram consideradas para análise, restando sete pesquisadoras. $\mathrm{O}$ Quadro 1 apresenta o perfil resumido delas.

Quando questionadas sobre a motivação para a escolha da área de Computação, cinco delas apontaram a aptidão com matemática como uma das razões. Duas citaram que foram motivadas por recomendação familiar, duas informaram que já tinham interesse específico na área, uma informou que já tinha parentes que trabalhavam na área e apenas uma citou que enxergava a Computação como uma profissão feminina também. Aspectos como ascensão social e retorno financeiro foram citados apenas duas vezes.

Durante a trajetória acadêmica e profissional, cinco delas mencionaram como desafios discriminação/preconceito por causa de sua cor/raça/etnia e duas mencionaram discriminação/preconceito por causa de gênero. Durante a trajetória profissional duas delas já pensaram ou pensam em desistir da área por condições inadequadas de trabalho e uma por outros interesses de pesquisa.

Ainda que elas mesmas tenham tido como desafios discriminação/preconceito por cor/raça/etnia ou gênero, cinco delas dizem não ter vivido ou presenciado atos racistas ou homofóbicos no cotidiano acadêmico no contexto da Computação, mas tem notícias de atos do gênero.

Em relação a questões financeiras, três mencionaram dificuldades financeiras 
durante a trajetória acadêmica, sendo que uma delas precisou interromper os estudos de nível superior em algum momento. Três trabalharam durante a graduação para se sustentar ou sustentar a família. Duas dessas três cursaram o mestrado sem bolsas de estudos e uma com bolsa parcial de estudos. As demais cursaram o mestrado integralmente com bolsa. $\mathrm{Na}$ fase de doutorado, excetuando-se as duas que não tiveram bolsa de estudos durante o mestrado, as demais cursaram o doutorado com bolsa de estudos integral. Das duas que cursaram o mestrado sem bolsa de estudos, uma cursou o doutorado com bolsa de estudos parcial e a outra não cursou o doutorado.

Quadro 1. Perfil resumido das professoras de cursos de pós-graduação stricto-sensu

\begin{tabular}{|c|c|c|c|c|}
\hline Área de Atuação & Faixa Etária & Região & Cor/Raça & Professora \\
\hline $\begin{array}{c}\text { Educação em Computação, } \\
\text { Informática na Educação, } \\
\text { Métodos Formais, Sistemas de } \\
\text { Informação, Ontologias }\end{array}$ & 45 a 49 anos & Nordeste & Parda & A \\
\hline $\begin{array}{c}\text { Arquitetura de Computadores e } \\
\text { Processamento de Alto } \\
\text { Desempenho, Sistemas de } \\
\text { Informação, Sistemas Multimídia } \\
\text { e Web }\end{array}$ & 40 a 44 anos & Sudeste & Parda & B \\
\hline $\begin{array}{c}\text { Algoritmos, Combinatória e } \\
\text { Otimização, Informática na } \\
\text { Educação, Inteligência Artificial, } \\
\text { Inteligência Computacional }\end{array}$ & 50 a 54 anos & Oeste & Preta & C \\
\hline $\begin{array}{c}\text { Banco de Dados, Engenharia de } \\
\text { Software }\end{array}$ & 30 a 34 anos & Sul & Parda & D \\
\hline $\begin{array}{c}\text { Educação em Computação, } \\
\text { Informática na Educação }\end{array}$ & 40 a 44 anos & Norte & Preta & E \\
\hline $\begin{array}{c}\text { Engenharia de Software, } \\
\text { Segurança da Informação e de } \\
\text { Sistemas Computacionais, } \\
\text { Sistemas Tolerantes a Falhas }\end{array}$ & 60 a 64 anos & Sudeste & Preta & F \\
\hline $\begin{array}{c}\text { Educação em Computação, } \\
\text { Informática na Educação, } \\
\text { Inteligência Artificial, } \\
\text { Computação e Sociedade }\end{array}$ & 45 a 49 anos & Nordeste & Parda & G \\
\hline
\end{tabular}

No que concerne a oportunidades de acesso ao ensino superior, nenhuma delas foram beneficiadas por cotas ou ações afirmativas em qualquer fase da vida acadêmica e das sete mulheres apenas três fizeram mestrado ou doutorado sanduíche no exterior. Três das professoras relatam que durante sua trajetória acadêmica tiveram colegas negros no mestrado ou doutorado e somente uma afirmou ter professores negros no mestrado ou doutorado.

Mesmo abrangendo uma gama de variáveis, o questionário ainda mostrou-se insuficiente para esta investigação, pois questões relacionadas à herança de preconceitos, trajetória escolar anterior à universidade, incentivos na infância para seguir na área de exatas, forma de tratamento pelos pares no ambiente de trabalho, 
dentre outros aspectos não puderam ser abordados. Desta forma, elas foram contatadas sobre a possibilidade de participar de entrevistas, sendo entrevistadas as professoras A, F e G. As reais identificações foram suprimidas por motivos éticos.

Por meio das entrevistas conseguimos relatos que seriam difíceis de exprimir nos questionários. A permanência dos estudantes em condições sociais e econômicas desfavoráveis era difícil mesmo quando este ia em busca de oportunidades, como pode ser visto no relato: "Ai ela disse "a secretária já me olhou de cima a baixo e aí eu falei para ela que eu tava vendo possibilidade de você vir de ter uma bolsa, de não sei o quê e ela já foi logo cortando". "Ah, sua filha não vai se dar bem aqui, porque o cursinho é muito puxado, porque precisa ter tido uma boa base no ensino fundamental e tal, porque não sei o quê", e minha mãe, "não, mas ela sempre foi muito boa aluna na escola", "ah, mas escola pública a senhora sabe como é que é" isso naquela época, quando escola pública ainda era muito boa. Mas na verdade o que minha mãe sentia: negro, pobre, aqui eu não quero." (Professora F)

É possível ver até mesmo reprodução de atos racistas por professores, como o relato da professora G: "Fui me lembrar...ainda no ensino o quê? fundamental...acho que fundamental II. Uma professora de português que isso ficou na minha cabeça...que eu chegava lá..aí ela...ela gostava de mim assim porque eu sempre fui muito boa aluna...aquela menina né, muito bem comportada. Mas ela chegou assim e falou: "mas minha filha, sua mãe não penteia seu cabelo não é quando você vem?" Aí puxava meu cabelo assim pra amarrar pra ficar com o coquezinho todo comportado. Agora eu pensei assim: Nossa, acho que a mulher...ela avaliava assim essa menina tão boa aluna, mas...Entendeu né? Esse tipo de coisas né?"

\section{Considerações finais}

A equipe continua analisando os dados levantados nessa pesquisa e pretende por meio de triangulação dos dados com a abordagem de Margolis et al. (2017), iniciar alguma teorização sobre esse tema no Brasil. Nessa teorização espera-se construir conhecimento sobre trajetória escolar e acadêmica dessas mulheres de modo que possam endereçar ações de fomento à participação feminina na Computação, especialmente pelas jovens, sejam elas negras ou não.

\section{Agradecimentos}

Agradecemos à Ford Foundation ${ }^{l}$ e à Fundação Carlos Chagas ${ }^{2}$ pelo provimento de recursos para financiamento desta pesquisa, por meio do Concurso de Pesquisa Negras e Negros nas Ciências.

\section{Referências}

Margolis, J.; Estrella, R.; Goode, J.; Holme, J. J.; Nao, K. (2017). Stuck in the Shallow End - Education, Race, and Computing. EUA, MIT Press.

Oliveira, A. C.; Moro, M. M.; Prates, R. O. (2014). Perfil Feminino em Computação: Análise Inicial. XXII Workshop sobre Educação em Computação, Brasília. In: Anais do XXIX Congresso da Sociedade Brasileira de Computação. Porto Alegre, SBC. p. $1465-1474$.

\footnotetext{
${ }^{1}$ www.fordfoundation.org

${ }^{2}$ www.fcc.org.br
} 